\title{
Relative Advantage of Assistive Technology in the Teaching and Learning of Integrated English Among the Visually Impaired Learners in Special Secondary Schools in Kenya
}

\author{
Grace Nyagah \\ University of Nairobi, Nairobi, Kenya \\ Reuben Nguyo Wachiuri \\ Catholic University of Eastern Africa (CUEA), Nairobi, Kenya \\ Rosemary Imonje \\ University of Nairobi, Nairobi, Kenya
}

\begin{abstract}
The Kenyan government's education policies and goals are geared towards achieving education for all (EFA) in tandem with international conventions and standards, including the Sustainable Development Goals ratified in November 2015. It is estimated that there are approximately 15,500 visually impaired (VI) children in Kenya. The Ministry of Education Report (2009) showed that 1,527 children were attending special schools and 1,637 were attending integrated/inclusive schools in the country. These special schools utilize assistive technology (AT) although facilities are inadequate. The study is based on Rogers' diffusion of innovation theory. The purpose of the study was to establish the relationship between relative advantage of AT (the degree to which an innovation was perceived better than the one it supersedes) and teaching and learning of integrated English among VI learners. The study employed descriptive research design, targeting all the four special secondary schools exclusively set aside for the VI in Kenya. The sample size was four principals, 218 students, and 48 teachers. Data were collected using questionnaires, observation schedule and focused group discussions. The study established that there was significant relationship between relative advantage of AT and teaching and learning of integrated English among VI learners. The study recommended that before acquisition of AT by school management, there should be objective assessment of whether an AT would add value to the learning process compared to the already existing AT.
\end{abstract}

Keywords: relative advantage, assistive technology (AT), visually impaired (VI), equity and special education

\section{Introduction}

Disability is an impairment that may be physical, cognitive, intellectual, and sensory, such as visually impaired (VI), hearing impaired, or developmental that results in restrictions of an individual's ability to participate in what is considered "normal" in their everyday societies. Specifically, visual impairment refers to

Grace Nyagah, Dr., senior lecturer \& immediate former chair, Department of Educational Administration and Planning, University of Nairobi.

Reuben Wachiuri Nguyo, Dr., lecturer, Department of Postgraduate Studies in Education, Catholic University of Eastern Africa (CUEA).

Rosemary Imonje, Dr., lecturer, Department of Educational Administration and Planning, University of Nairobi. 
greatly reduced or decreased ability to see that causes problems that cannot be fixed by usual means, such as glasses. Disabilities impact negatively on the teaching and learning process, hence, the need for assistive technology (AT). AT is a broad concept, covering anything that might be used to compensate for lack of certain abilities (Reed \& Bowser, 2005). These devices range from low-tech devices like special grip for a pen, to more advanced items like hearing aids and glasses, to high-tech devices, such as braille's and computers with specialized software for helping persons to read (World Health Organization [WHO], 2009; Petty, 2012). The United Nations defines AT as "technology adapted or specially designed to improve the functioning of people with disabilities" (Borg, Lindstrom, \& Larsson, 2009, p. 1863).

It is the right of every VI person to have access to equal quality education same as that of sighted learners (United Nations, 2006). To bridge the gap in regard to access of quality education between sighted and the VI students, governments must develop feasible policies that enhance equity in education for both sighted and VI students. At a global level, a national study in the USA that targeted 128 teachers of the VI and 64 administrators in 20 regions concluded that "most children are not receiving the access mandated by law, despite several national efforts" (Smith, Geruschat, \& Huebner, 2004, p. 624). Teachers' and administrators' lack of knowledge and training in both the law and the use of AT were cited as possible reasons for the lack of access to education. Both sighted and VI students share a core curriculum, which includes areas of study deemed important by the school. In Kentucky State in USA, students with visual impairments require expanded training in areas specific to VI known as the expanded core curriculum. This model was adopted by many educators of the visually impairments to meet additional needs of the VI students (Corn, DePreist, \& Erin, 2000). The expanded version addresses the need for access to the curriculum through the use of ATs.

According to a survey carried out in Kenya, $10 \%$ of VI learners attend secondary schools, only $25 \%$ of VI learners attend primary schools. This is despite a relatively well developed inclusive education system (Williams, 2013). According to Victoria (2015) of Sight Savers Organization, a Non-Governmental Organization (NGO) which has been promoting inclusive education in Kenya, the school curriculum in Kenya has been changing regularly with recommended text books changing almost on a yearly basis. This phenomenon poses a great challenge for learners with visual impairment as producing a single text book in Braille takes over four months. Thus, these students often finish a whole year without appropriate text books. This indicates that there is no level platform for VI with the sighted students in the learning process.

\section{Statement of the Problem}

In 2009, the Ministry of Education (MOE) released a report which indicated that only $21 \%$ of VI children were attending school. This indicates that the majority (79\%) of VI children do not have access to education. It was estimated that there are approximately 15,500 visually disabled children in Kenya. The MOE Report (2009) showed that 1,527 children were attending special schools and 1,637 were attending integrated/inclusive schools in Kenya.

The Kenya Institute of Special Education (KISE) that trains personnel for disabled persons has AT, such as the Duxbury Braille Translator, the Dolphin Pens, and Jaws for Windows (Ministry of Education, 2012). These technologies are too expensive, for instance, a single Dolphin pen costs approximately $\$ 150$ and are not available in all schools (A Dolphin Pen is USB drive in AT which the users can use the magnification speech and Braile support to any personal computer). This indicates that there may be a problem of teaching and 
learning of VI students due to inadequacy or unavailability of AT. KISE has assisted in facilitating availability of AT devices in some schools, but have not been effectively utilized to enhance teaching and learning among VI students. According to Bisi (2013) AT, such as talk book were available but inadequate. Another study by Andoh (2012), observed that despite investments on information communication technology (ICT) infrastructure, equipments and professional development to improve education in many countries, ICT adoption and integration in teaching and learning have been limited. Therefore, there was need to determine the effect of relative advantage of AT in teaching and learning of integrated English among VI learners in special secondary schools in Kenya.

\section{Purpose of the Study}

The purpose of the study was to determine the relationship between relative advantage of AT and teaching and learning of integrated English among VI learners in special secondary schools in Kenya.

\section{Objective of the Study}

To examine the extent to which relative advantage of AT affects teaching and learning of integrated English among the VI learners.

\section{Research Hypothesis}

The null hypothesis for this study was that there is no significant relationship between relative advantage of AT and teaching and learning of integrated English among the VI learners.

\section{Theoretical Framework}

The study was based on diffusion of innovations theory by Rogers (2003). He stated that technologies should exhibit a relative advantage over other options for them to be adopted. For a person to choose to use a technology for a specified task, it should provide some forms of benefit for the task concerned. To be more specific, the innovation should demonstrate a relative advantage over other options, ideally including the technology currently used for the task. However, other factors come into play in the selection including increased performance, cheaper costs, increased social standing, or even other factors may all contribute to the sense of relative advantage (Jacobsen, 1998).

Rogers categorized innovations into two types: preventive and incremental (non-preventive) innovations. A preventive innovation is a new idea that an individual adopts now in order to lower the probability of some unwanted future condition. Preventive innovations usually have a slow rate of adoption so their relative advantage is highly uncertain. However, incremental innovations provide beneficial outcomes in a short period (Surendra, 2001).

If teachers see that technology has value in their instruction, then they will use it (Finley, 2003; McKenzie, 2001; Parisot, 1995; Spotts, 1999). Casmar (2001) argued that when faculty members face the new demands placed on them, they will adopt technology. To integrate technology successfully into teacher education courses, teacher education faculty should see the need providing helpful experiences for themselves and their students (Schmidt, 1995). To increase the rate of adopting innovations and to make relative advantage more effective, direct or indirect financial payment incentives may be used to support the individuals of a social system in adopting an innovation. Incentives are part of support and motivation factors. 


\section{Literature Review}

According to Andoh (2012), global investment in ICT to improve teaching and learning in schools have been initiated by many governments. The government spending on educational ICT in September 2008 in the UK was £2.5bn (Nut, 2010), in United States, the expenditure on K-12 schools and higher education institutions was $\$ 6$ billion and $\$ 4.7$ billion respectively in 2009 (Nut, 2010). In New Zealand, the government spends over \$410 million every year on schools ICT infrastructure (Johnson, Calvert, \& Raggert, 2009). Despite all these investments on ICT infrastructure, equipments, and professional development to improve education in many countries, there is little evidence of ICT adoption and use in teaching and learning especially in Turkey (Gulbahar, 2007). This scenario suggests that education sector is investing heavily on ICT but its adoption behind the business sector (Leidner \& Jarvenpaa, 1995).

In Canada, students with disabilities who effectively use ATs are more independent and better able to keep pace with demands of college programs (Brokop \& McIntosh 2009). They are more likely to apply their knowledge of AT across subject areas and into their personal lives. AT can have positive effects on student engagement and on the related issues of independence and completion of courses. Success is influenced by variables, such as accurate and timely ATs assessments, knowledgeable and skilled staff, timely application of AT and prior learning of computer skills. According to studies in Illinois (Kapperman, Sticken, and Heinze, 2002) and Kentucky (Abner \& Lahm, 2002), only half of kindergarten through 12th grade (K-12) students with visual impairments received AT services.

National data collected in the USA by the Special Education Elementary Longitudinal Study (SEELS), showed similar low usage of AT (Kelly, 2008). The results of Kelly's study specified that well over half of students with VI used no AT. In a nationwide survey in the same country, it was revealed that $42 \%$ of teachers of the VI (TVIs) listed "becoming proficient users of AT" as the primary goal for their students (Thurlow, Johnstone, Timmons, \& Altman, 2007). In 2005, every student at the Kentucky School for the Blind (KSB) had AT listed as an adaptation, accommodation, or modification on their individual educational plan (IEP). This demonstrated the importance given to AT by students, parents, and professionals who make up the IEP committees at KSB (Hume, 2006).

A 2002 statewide survey of teachers of the VI in Illinois showed that only $40 \%$ of students requiring alternative reading formats used AT. The authors of this study concluded that, "A significant number of VI students in Illinois who could benefit from AT were not receiving instruction in that area" (Kappennan, 2002, pp. 107-108). In another 2002 survey of Kentucky teachers of the VI showed that $31.9 \%$ of their students used screen enlargement technologies (Abner \& Lahm, 2002). This was followed by no accommodation at all (27.7\%) and screen reading technologies (19.5\%). In this study, teachers of the VI reported that only $2 \%$ of all their students were using refreshable Braille devices. In an examination of data from the nationwide SEELS, it was found that 18\% of students with visual impairment in the school years 2000-2001 and 2001-2002 used high tech AT (Kelly, 2008). When counting only students with visual impairment considered being "academically oriented," this study found that 41\% in the year 2000-2001 and 39\% in the year 2001-2002 used high tech AT.

The barriers to successful and effective use of AT devices relate to several factors, such as limited financial resources (G. Fifield \& B. Fifield, 1997), high cost of equipment (Wehmeyer, 1998), a lack of knowledge and support from teachers (Alper \& Raharinirina, 2006), and eligibility issues for possessing devices (Zhang, 2000). According to Johnson (2011), lack of knowledge and awareness among people with 
disabilities, reluctance to use the devices, poor device performance, changes in needs or priorities, and feelings of stigmatization were the main reasons for the underuse of AT devices.

Kelly (2008) further investigated the use of AT among students who were VI in the USA. The study estimates the level of AT experience with text-to-speech devices and screen reading software nationwide, and some of the contextual circumstances that may have contributed to the use of this special technology for the VI. The key finding of the study was that the vast majority of students with visual impairment in the USA were not using adequate AT. According to a report by the National Federation of the Blind, nearly $90 \%$ of America's blind children were not learning to read and write, because they are not being taught Braille or given access to it. There is a Braille literacy crisis in America. The American Foundation for the Blind (1996) estimated that fewer than $10 \%$ of people who were legally blind in the United States and fewer than $40 \%$ of the estimated number who were functionally blind are Braille readers. The American Printing House for the Blind estimated the Braille literacy rate among children to be around $10 \%$. Experts estimate 1.3 million blind people live in the United States, and approximately 75,000 people lose all or part of their vision each year.

Given the diversity of ATs for persons with visual impairment, teachers in the USA were unfamiliar with the diverse types of AT available for specific needs. Students may require AT for support including speech access, Braille access, large print access, tactile communication systems, or any combination of these modes. In addition, teachers understood AT, ICT, and web educational packages designed for general instruction to be collectively understood as ATs. Not knowing what AT devices are available and the varied understanding of general applications result in ATs not being fully adopted and utilized to benefit students. While all teachers possessed limited skills and knowledge in AT, a handful of teachers emerged as champions of AT to varying degrees. This undermines the effective implementation of AT by the teachers. It also poses a challenge in equitable distribution amongst the three VI categories as classified by WHO (American Association for the Advancement of Science [AAAS], 1991).

Stefanich and Norman's (1996) survey found that $73.7 \%$ of K-12 science teachers and university science educators disagreed with the statement that "I am more comfortable in a setting in which there are no people with visual disabilities" (p. 19). Also, $69.8 \%$ of those surveyed did not believe that "It is unrealistic to expect a blind student to be a chemist" (p. 18). Individuals with Disabilities Education Act (IDEA) in the United States require that students with disabilities receive full access to education. According to the AAAS (1991), "The full potential of many of the students with disabilities are not yet being realized" (p. 8). How to increase the participation of students with disabilities, especially those with visual impairments in science education is a critical issue.

In Australia, a survey conducted indicated that most VI learners attend public funded schools (Jolley, Steer, Gale, \& Gentle, 2001). Respondents' estimates revealed that there were approximately 4,500 students who were VI attending Australian public and private sector primary and secondary level systems or agency educational programmes. Of the 4,500 students reported, some 2,700 did not have an intellectual disability that precluded them from using print or braille to attain literacy and numeracy. Estimated numbers by gender indicated that 755 were female and 1,845 were male (Åke, Nena, \& Hannu, 2010). When latest version of ATs in Australian public schools was introduced and a policy of maintenance and monitoring introduced there was a great migration of VI students from private schools to public schools and also high level of enrolment of VI learners.

The rapid development of ICT has impacted on the education sector in South Africa. According to Microlink (2015), AT delivered greater inclusivity in education and the working environment by empowering 
individuals to achieve their true potential. The outcome of AT provision and training has resulted in empowerment of the VI people to live, work, and study on an equal playing field.

In East Africa, according to Sight Savers Tanzania's annual review report (2010), less than $10 \%$ of children who are blind or visually impaired (B/VI) or who have low vision (LV) receive any kind of schooling. Realizing the effectiveness of AT in education for people with disabilities, tanzania education authority (TEA), tanzania league for the blind (TLB), and sight savers tanzania (SST) have worked closely since 2009 to ensure the "Dolphin Pen" project which started in Kenya is scaled up in Tanzania, so that students with visual impairment also benefit. Tanzania Education Authority, Tanzania League for the Blind, and Sight Savers Tanzania jointly developed an “Assistive Technology Programme” (SST Annual Review Report, 2010).

\section{Relative Advantage and Teaching and Learning}

The increase in AT use may be attributed to the laws passed which support funding for AT devices and services. Although these laws increase the accessibility of AT, many recipients are dissatisfied with devices and services. Dissatisfaction typically results in discontinuance of the use of AT devices (De Marez, Evens, \& Stragier, 2011).

According to Medcalf (2015), it is estimated that there are 28.5 million individuals affected by some form of visual impairment globally. Among this population 24.6 million have low vision and 39 million are blind. Griffiths and Price (2011) indicated that there is need to involve people from different backgrounds when choosing AT for an individual, and suggest that a framework is needed to assist decision-making that encompasses all the different viewpoints which may come into play. This multidisciplinary approach can be vital in order to take into account all the factors which play a part in developing and deploying effective technological solutions for people with special educational needs. A national survey in USA on technology abandonment found that $29.3 \%$ of all devices obtained were abandoned (Phillips \& Zhao, 1993). Discontinuance of AT represents a waste of time and money. There is, however, limited research documenting factors related to AT discontinuance from the consumers' perspectives. It is important to gain an understanding of these factors to aid professionals in designing AT service delivery techniques. Rogers' (2003) diffusion of innovation theory has been the main starting point for much research into technology innovation and adoption domains, and still provides a widely used framework for forecasting purposes, service and infrastructure requirements, business modeling and policy measurements (De Marez, Evens, \& Stragier, 2011). Rogers' (2003) model is based on five aspects: compatibility, complexity, trialability, relative advantage, and observability.

Rogers (2003) argued that innovations offering more relative advantage will be adopted faster than other innovations. Rogers (2003), however, cautioned that, "getting a new idea adopted, even when it has obvious advantages, is difficult" (p. 1), so the availability of relative advantage of innovations speeds up the innovation-diffusion process. Diffusion theorists claim that innovations that are perceived by individuals as having greater relative advantage will be rapidly adopted and slowly discontinued (Rogers, 1995). Relative advantage is examined in the present study to determine if it influences teaching and learning process for the VI students.

\section{Research Methodology}

This study used the descriptive survey design which is a method of collecting information concerning the current status of the phenomena to describe "what exists" with respect to variables or conditions in a situation 
(Orodho, 2003). According to Ministry of Education (2012), there are only four public high schools for the blind in Kenya. Thika School for the blind (central region), St. Lucy's High School for the blind (Meru) (eastern region), Kibos High School for the blind (western region), and St Francis Kapenguria (Rift valley Region). This study targeted all the four principals, 48 teachers and 480 students. A sample of 218 students was used while the principals and teachers were purposively selected. Data were analyzed through the use of descriptive and inferential statistics.

\section{Findings and Discussions}

The objective of the study was to examine the extent to which relative advantage of AT affects teaching and learning of integrated English among the VI learners. The null hypothes is that, there is no significant relationship between relative advantage of AT and teaching and learning of integrated English among the VI learners was tested at 0.05 significance level. Table 1 indicates the relationship between relative advantage and teaching and learning.

Table 1

Relationship Between Relative Advantage and Teaching and Learning

\begin{tabular}{|c|c|c|c|c|c|c|c|}
\hline Model & $R$ & \multicolumn{2}{|c|}{$R$ square } & Adjusted $R$ square & \multicolumn{3}{|c|}{ Std. error of the estimate } \\
\hline 1 & $0.053^{\mathrm{a}}$ & 0.003 & & 0.002 & \multicolumn{2}{|c|}{1.05349} & \\
\hline \multirow[t]{2}{*}{ Model } & & Sum of squares & Df & Mean square & $F$ & \multicolumn{2}{|c|}{ Sig. } \\
\hline & Regression & 0.131 & 1 & 0.131 & & \multirow{3}{*}{\multicolumn{2}{|c|}{$0.001^{\mathrm{b}}$}} \\
\hline \multirow[t]{2}{*}{1} & Residual & 46.614 & 42 & 1.110 & 0.118 & & \\
\hline & Total & 46.744 & 43 & & & & \\
\hline \multirow{2}{*}{ Model } & & \multicolumn{2}{|c|}{ Unstandardized coefficients } & \multicolumn{2}{|c|}{ Standardized coefficients } & & \multirow{2}{*}{ Sig. } \\
\hline & & $\mathrm{B}$ & Std. error & B & & & \\
\hline \multirow{2}{*}{1} & (Constant) & 6.336 & 0.959 & & & 6.608 & 0.000 \\
\hline & Relative advantage & 0.088 & 0.255 & 0.053 & & 0.343 & 0.001 \\
\hline
\end{tabular}

Notes. a. Dependent variable: teaching and learning;

b. Predictors: (constant), relative advantage.

The coefficient of determination was 0.003 indicating that relative advantage of AT explained $0.3 \%$ of variation in teaching and learning among the VI learners. The remaining $99.7 \%$ could be explained by other variables not within the study. The overall test of significance using $F$-value statistic was 0.118 which was significant because $p$-value $(0.001)$ is less than 0.05 level of significance and the null hypothesis was consequently rejected. This means that relative advantage significantly influences teaching and learning among VI in special secondary school in Kenya. The findings of this study do not concur with those of Alper and Vaharihinna (2006) who asserted that AT may not be fully beneficial to the users. However, Finley (2003) showed that relative advantage of an AT had no significant effect on its usability by VI learners.

\section{Conclusion}

The study established that there is a significant relationship between relative advantage of AT and teaching and learning of integrated English among the VI learners. This means that the relative advantage of AT does significantly influence teaching and learning of VI learners in special secondary schools in Kenya. 


\section{Recommendations}

There should be objective assessment of whether an AT would add value compared to the already existing low-tech ATs. The school management should therefore carefully determine whether an AT would make a difference to the VI learners in the learning process.

Schools should benchmark with other special secondary schools locally and internationally on the use of different AT devices which would enable the school to understand how other schools have benefited from their use. This would facilitate the management on whether they need to completely do away with existing AT and replace with new AT.

The schools' principals should involve people from different backgrounds when choosing AT for an individual, and suggest a framework that will assist in decision-making which encompasses all the different viewpoints which may come into play. This multidisciplinary approach can be vital in order to take into account all the factors that play a part in developing and deploying effective technological solutions for people with special educational needs.

The principals should work closely with key stakeholders to invest in AT that would be of relative advantage to the users.

\section{References}

Abner, G. H., \& Lahm, E. A. (2002). Implementation of assistive technology with students who are visually impaired: Teachers' rediness. Journal of Visual Impairment \& Blindness, 96(2), 98-105.

Alper, S., \& Raharinirina, S. (2006). Assistive Technology for individuals with disabilities: A review and synthesis of the literature. Journal of Special Education Technology, 21(2), 47-64.

Åke, G., Nena, L., \& Hannu, L. (2010). Effective use of assistive technologies for inclusive education in developing countries: Issues and challenges from two case studies. International Journal of Education and Development Using Information and Communication Technology, 6(4), 5-26.

American Association for the Advancement of Science. (1991). Laboratories and classrooms in science and engineering. Washington, D.C.: U.S. Government Printing Office.

American Foundation for the Blind. (1996). Estimated number of adult braille readers in the United States. Journal of Visual Impairment \& Blindness, 3(90), 287.

Andoh-Charles, B. (2012). Factors influencing teachers' adoption and integration of information and communication technology into teaching: A review of the literature. International Journal of Education and Development Using Information and Communication Technology (IJEDICT), 8(1), 136-155.

Bennett, J., \& Bennett, L. (2003). A review of factors that influence the diffusion of innovation when structuring faculty-training program. Internet and Higher Education, 6, 53-63.

Bisi, F. M. (2013). Impact of assistive technology intervention on visually Impaired student performance in Kiswahili in public primary teachers college in Kenya (Unpublished Ph.D. thesis, University of Nairobi).

Borg, J., Lindstrom, A., \& Larsson, S. (2009). Assistive technology in developing countries: National and international responsibilities to implement the convention on the rights of persons with disabilities. Lancet, 374(28), $1863-1865$.

Brokop, F., \& McIntosh, S. (2009). Context situated assistive technology training and its impact on engagement, learning outcomes, and assistive technology adoption. Canada: NorQuest College.

Casmar, S. P. (2001). The adoption of computer technology by faculty in a college of education: An analysis of administrative planning issues (Doctoral dissertation, Washington State University).

Com, A. L., DePreist, L. B., \& Erin, J. N. (2000). Visual efficiency. In M. C. Holbrook \& A. J. Koenig (Eds.), Foundations of education: Volume II. Instructional strategies for teaching children and youths with visual impairments (2nd ed., pp. 464-499). New York: AFB Press.

De Marez, L., Evens, T., \& Stragier, J. (2011). Diffusion theory vs. today’s ICT environment. Observatorio (OBS*) Journal, 5(3), $175-202$. 
Fifield, M. G., \& Fifield, M. B. (1997). Education and training of individuals involved in delivery of assistive technology devices. Technology and Disability, 6, 77-88.

Finley, T. R. (2003). A descriptive study of utilization of technology from a perspective of full-time faculty in Virginia's higher education teacher-education programs (Doctoral dissertation, The George Washington University).

Gülbahar, Y. (2007). Technology planning: A roadmap to successful technology integration in schools. Computers \& Education, 4(49), 943-956.

Hume, D. (2006). Kentucky school for the blind 3-year assistive technology plan. Louisville, K.Y.: Kentucky School for the Blind.

Kapperman, G., Sticken, J., \& Heinze, T. (2002). Survey of the use of assistive technology by Illinois students who are visuallly impaired. Journal of Visual Impairement and Blindness, 96, 106-108.

Kelly, S. M. (2008). Correlates of assistive technology use by students who are visually impaired in the U.S.: Multilevel modeling of the special education elementary longitudinal study. The Association for Education and Rehabilitation of the Blind and Visually Impaired International Conference, Chicago, IL.

Johnson, D. (2011). Why is assistive technology underused? Library Hi Tech News, 16(6), 15-17.

Johnson, M., Calvert, E., \& Raggert, N. (2009). ICT in schools final report. Retrieved November 12, 2011, from http://www.2020.org.nz/template/ict_09___online_final_.pdf

Jolley, W., Steer, M., Gale, G., \& Gentle, F. (2001). Literacy and numeracy acquisition including the role of braille for students in Australia who are blind or vision impaired (Unpublished research report). Canberra: Department of Education, Employment \& Youth Affairs.

Leidner, D. E., \& Jarvenpaa, S. L. (1995). The use of information technology to enhance management school education. A theoretical view. MIS Quarterly, 265-291.

McKenzie, J. (2001). How teacher learn technology best. From Now on: The Educational Technology Journal, 10(6). Retrieved March 1, 2005, from http://www.fno.org/mar01/howlearn.html

Nasser, S. (2015). What will a diverse and inclusive workplace look like in future? Assistive Technology Company, Microlink PC (UK) Limited.

Nut, J. (2010). Professional educators and the evolving role of ICT in schools: Perspective report. Retrieved November 12, 2011, from http://www.ictliteracy.info/rf.pdf/ICTinSchools.pdf

Orodho, A. J. (2003). Essentials of educational and social sciences research method. Nairobi: Masola publishers.

Parisot, A. H. (1995). Technology and teaching: The adoption and diffusion of technological innovations by a community college faculty (Doctoral dissertation, Montana State University). ProQuest Digital Dissertations (UMI No.AAT 9542260)

Petty, R. E. (2012). Technology access in the workplace and higher education for persons with visual impairments: An examination of barriers and discussion of solutions. Houston, Texas: Independent Living Research Utilization at TIRR.

Reed, P., \& Bowser, G. (2005). Assistive technologies and the IEP. In D. Edyburn, K. Higgins, \& R. Boone (Eds.), Handbook of special education technology research and practice, knowledge. Whitefish Bay: Design Inc..

Republic of Kenya. (2010). Ministry of education, enrolment of visually impaired learner. Nairobi: Government Printer.

Rogers, E. M. (2003). Diffusion of innovations. New York, N.Y.: Free Press.

Free Press Schmidt, D. (1995). Use and integration of computer-related technology in teaching by pre service teacher education faculty (Doctoral dissertation, Iowa State University). ProQuest Digital Dissertations (UMI No.AAT 9610982)

Schmidt, D. (1995). Use and integration of computer-related technology in teaching by preservice teacher education faculty (Doctoral dissertation, Iowa State University). ProQuest Digital Dissertations (UMI No. AAT 9610982)

Sight Savers Tanzania: (2010). Annual report and financial statements. United Kingdom: West Sussex, RH16 4BX.

Smith, A. J., Geruschat, D., \& Huebner, K. M. (2004). Policy to practice: Teachers' and administrators' views on curricular access by students with low vision. Journal of Visual Impairment \& Blindness, 98(10), 612-628.

Spotts, T. H. (1999). Discriminating factors in faculty use of instructional technology in higher education. Educational Technology \& Society, 2(4), 92-99.

Stefanich, G. P., \& Norman, K. I. (1996). Teaching science to students with disabilities: Experiences and perceptions of classroom teachers and science educators. A special publication of the Association for the Education of Teachers in Science.

Surendra, S. S. (2001). Acceptance of Web technology-based education by professors and administrators of a college of applied arts and technology in Ontario (Doctoral dissertation, University of Toronto). ProQuest Digital Dissertations (UMI No. AAT NQ58603)

Thurlow, M., Johnstone, C., Timmons, J., \& Altman, J. (2007). Survey of teachers of students with visual impairments: Students served and their access to state assessments of reading. Minneapolis, M.N.: University of Minnesota. 
United Nations. (2006). Convention on the rights of persons with disabilities: Getting all children into school and helping them learn. UNESCO Final Report: Regional Workshop on Inclusive Education.

Victoria, C. A. (2015). Australian Bureau of Statistics. Locked Bag 10.

Wehmeyer, M. L. (1998). National survey of the use of assistive technology by adults with mental retardation. Mental Retardation, $36,44-51$.

World Health Organization (WHO). (2009). Magnitude and causes of visual impairment: 2009-2013 Action Plan. WHO, Geneva 27, Switzerland.

Zhang, Y. (2000). Technology and the writing skills of students with learning disabilities. Journal of Research on Computing in Education, 32(4), 467-479. 